\title{
Measuring Success: The Value of Our Work Can't Always Be Captured in a Spreadsheet
}

\author{
By Tom Radko, Editorial Director
}

\section{7 his year we were fortunate in encouraging directors of four university presses-Temple, Fordham, Virginia, and Colo-}

rado- to carve a chunk of time out of busy winter schedules in order to share their perspectives on the university press enterprise. We gave each a generous 1000-1500 words (a magnificent allotment in Choice's 190-word-review world) to share his/her reflections, be they on the particular press or on university presses as a whole. The essays follow, and I hope you agree that they do not disappoint with their message of how central university presses are to the grand theme of things academic.

Linked to this forum is a listing of titles deemed by university presses to be particularly valuable to the audiences Choice has served for over fifty years: librarians, faculty, students, scholars, and the public interested in academic materials. We would like to thank both our contributors for their time in crafting such thoughtful narratives and the university presses that mined their rich title listings for the books most suitable for the audiences we servewith a special eye on undergraduates. We hope you find much in this forum that stimulates your imagination, encourages dialogue, and successfully acknowledges the immense value of university presses in our culture-a value that cannot be fully measured by the spreadsheet alone.-TRR

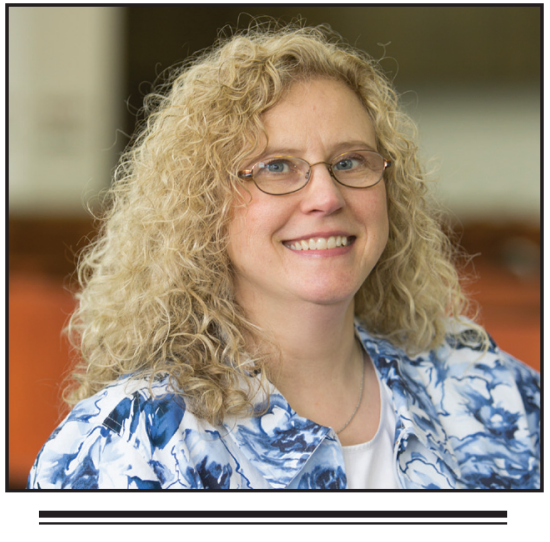

\section{Mary Rose Muccie}

Director, Temple University Press

Scholarly Communications

Officer, Temple University Libraries

How does a press like Temple define success? Is it by the number of books published each year? The number of authors who publish a second (or third) book with us? The awards our books win? The number of Outstanding Academic Titles in Choice? A positive bottom line? In a word, yes. If only there was a single criterion or set of criteria I as a press director could point to and declare, "We're a success!"

But wait, you might be saying. We hear all the time about the financial pressures facing university presses, so surely if you break even you're a success. The pressures are real, the challenges significant, and they keep many of us up at night. Balancing cost recovery with scholarly impact can mean walking a tightrope worthy of a Wallenda. It's a fact that balanced books are a black-and-white requirement for a business's viability. But as any press employee will tell you, the value of their work is measured in ways that can't be captured in a spreadsheet.
My definition of success starts with the active part we and other university presses play in the scholarly conversation. Over time, we've carefully created strong networks of scholars and experts with whom we work to identify disciplinary trends and the people doing interesting, new, and impactful work. The acquisitions editors know our strengths in a given discipline, which for a small press like Temple is usually a niche or an emerging area within the larger discipline. They reach out to scholars, travel to conferences, and make regular visits to campuses, talking to researchers about both their field and their work within it. Editors and potential authors determine together whether there is a possible Temple University Press book there.

Making a name for ourselves as a university press dedicated to smaller areas means taking risks, and our willingness to take these risks enriches and expands the discipline itself and gives researchers the ability to publish work that pushes the larger field in interesting new directions. We're fortunate to have a particularly salient example in our Asian American History and Culture series, which since 1991 has published numerous books that expanded the definition of the discipline. A recent example of a risky move on our part was the launch in 2014 of our first journal, Kalfou: A Journal of Comparative and Relational Ethnic Studies. It's rough going for new journals in niche areas, but there's no doubt that Kalfou is worth the risk. It provides a much-needed home for an evolving interdisciplinary approach to ethnic studies, social movements, and social justice and is a crossroads for academics, artists, and activists. 
On a local level, each time we're able to work with authors to bring documents and images held in our host university's library collections to the attention of a larger audience, we successfully achieve two of our main goals: to partner with the university library, which we're part of in a tangible way, and to be a valuable and relevant asset to the university as a whole. Of course, we're far from unique in our goal of an active presslibrary partnership. Last year's university press issue of Choice contained articles by six university press directors, including my predecessor, on aspects of press-library relationships. Those articles, as well as numerous other articles, blog posts, conference presentations, and casual conversations, discuss partnerships between presses and libraries in support of scholarly communications and alternate publishing streams.

At Temple, our developing scholarly communications partnership is built on a strong foundation. Long before there were open educational resources or journals built on top of institutional repositories, press authors, editors, and university librarians worked together to take advantage of the significant content in the Temple library's special collections. The authors do research and work closely with librarians in the Special Collections Research Center to identify the documents that support and enhance their manuscripts. Many press books feature content from the Urban Archives. Envisioning Emancipation, by Deborah Willis and Barbara Krauthamer, which was a press bestseller and won the 2014 NAACP Image Award for Outstanding Literary Work-Non-Fiction, contains numerous images from the Temple library's Charles L. Blockson Afro-American Collection. And the electronic edition of Kalfou wouldn't have been possible without our library's technical team.

Our success is also measured by the willingness of other organizations to work with us, and here we align with one of Temple's main goals as an urban university, that is, partnering with the city and region to enhance, improve, and promote both. Press books have used images from the Free Library of Philadelphia, the Library Company of Philadelphia, and the collections of the Pennsylvania Historical Society, all of which we've worked with several times. One of our most visible, and visual, collaborations is with the Mural Arts Program of Philadelphia, with which we published three books chronicling art created under the auspices of one of the largest and most successful public art organizations in the country. The Mural Arts Program is committed to empowerment and healing around the difficult issues depicted in the murals, while at the same time transforming the city's landscape, a mission we enthusiastically support. We've also collaborated with the Philadelphia Museum of Art, the Philadelphia Orchestra, the Pennsylvania Horticultural Society, and many other local institutions, all of which help broaden our outreach into the local and regional community.

As I mentioned above, such collaborations emphasize the Press as an asset to our home institution. Universities, like presses, are businesses with specific goals. They have customers, not the least of whom are their students and the students' parents. A successful press helps the university achieve its goals and serve its customers, and we just started work to integrate the Press with Temple courses. Undergraduate students in the Temple business school's Digital Design and Innovation class will spend the spring 2015 semester prototyping three possible products based on Press content. One of these is an app for Forgotten Philadelphia: Lost Architecture of the Quaker City, by local historian Tom Keels, one of the titles to use photos from the library's Urban Archives. Integrating this work into a for-credit course that provides tangible experience for students, practical benefits for the Press, and exposure for library collections provides an opportunity for several important parts of the university to work together on disseminating Temple's work.

Support for pedagogy in general is also crucial to our success as both a part of the scholarly conversation and a publisher of course books. Many of our books are adopted for use in courses throughout the world. Several have free curriculum/study guides available on our website, designed to help students and teachers make the best use of the content. Every course adoption is another mark in the success column for the author, the professor, and us as a press.

To come full circle, Temple University Press's success is measured by many yardsticks. We play an active role in scholarship and pedagogy. We forge partnerships with key constituents within and beyond the university. We support the mission of the university in valuable ways. We publish great titles that are read widely. And with all that, we do our best to balance the books.

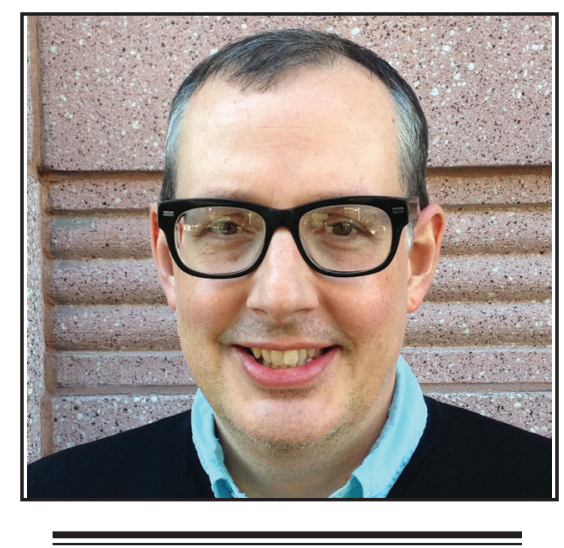

Fredric Nachbaur

Director, Fordham University Press

Flipping through The New York Times on December 27, I stopped turning the page when I came across an article about Kindle Unlimited and how self-published authors are up in arms about the new subscription service offered by Amazon. Like Netflix and Hulu for movies and Spotify for music, Kindle Unlimited offers access to more than 700,000 books, both traditional and self-published, for a monthly fee of \$9.99. Authors are making less money for the subscription than for individual purchases of their books. This is really quite far removed from my world of academic publishing - though one day Fordham University Press (FUP) books may be part of the offerings - but it's just one example of the surfeit of media that enters my orbit, whether through traditional print publications, social media feeds, websites, blogs, email, or mobile apps. I am inundated with information about digital technology and the changing face of publishing.

Pondering this issue in tandem with being invited to write an article about the state of publishing from the perspective of a small university press made me realize that I need to get down to the basics of what Fordham University Press does as an academic publisher and the contribution it makes to the humanities and the university. Despite dire predictions and the "sky is falling" mentality, we have managed to grow during the past five years since my appointment as director. How did we do it, and can we continue to sustain this level of growth? As with most university presses, we are subsidized by our parent institution and under constant pressure to reduce the amount of funding we receive. Part of my job as director is to promote advocacy for the Press. 
What it comes down to is that we publish really good books, books that get recognized in the media, both mainstream and academic. They win scholarly prizes, get adopted for courses, and are cited in journal articles and monographs. One of our recent translations, La Nostalgie by Barbara Cassin, was just awarded the French Voices Grand Prize given by the French Cultural Services and PEN American Center. All these accolades help contribute to elevating the profile of the Press and making us a destination for scholars looking for a good home for their manuscripts. A major force contributing to our ability to acquire outstanding books was our former Editorial Director, Helen Tartar, who worked at the Press for more than ten years. Dedicated to academic publishing, she made it her mission to publish smart interdisciplinary scholarship that pushed the boundaries. Because of her astute editorial skills combined with the commitment of an in-house staff, we were able to grow our list in both quantity and quality, no small feat in today's insecure environment. Though Helen died in spring 2014, her legacy lives on through the books she acquired. Helen created a community, and her vision will live on through that community and the many books she published, and in the many more books that will be published by members of that community inspired by Helen's vision. Richard Morrison, our new editorial director, has already proven himself a fierce champion of academic publishing. His background at the University of Minnesota Press and Duke University Press has given him the skills to lead FUP to new heights. All of this helps provide ammunition when dealing with the administration in promoting the Press's importance to scholarly communication and reinforcement of the university's main mission: to further academic excellence. We do it. First and foremost, that is the key role of a university press.

Establishing a strong reputation for scholarly content lays the foundation for creating new formats and new channels of distribution. It would be foolhardy to ignore digital opportunities, but it is important to recognize your limitations and to create strategic partnerships. With a small staff of ten people publishing up to and sometime surpassing 100 books annually, we don't have the resources to develop our own platform or to deal with major online e-tailers directly. We did have the wherewithal to develop a front-end XML workflow so that we were ready to meet the demands of existing and future trading partners. Being a small press can mean existing in a precarious environment in which we don't have the power to influence major players. Signing with Oxford University Press in 2011 to be our distributor for print and digital books in North America has proven extremely successful in confronting this issue. When I meet with potential authors, my elevator pitch mentions the benefits of not only dealing with a boutique operation like FUP, where you will receive close attention from editorial, production, and marketing but also benefiting from the heft of Oxford once the book publishes, at which point it will receive strong market penetration and wide distribution.

Fortunately, University Press Scholarship Online (UPSO) was opened up to university presses around the same time I signed the distribution agreement, and FUP was the first non-Oxford client invited to participate. This allowed us to take advantage of a proven platform that was highly regarded by librarians in addition to being heavily supported by Oxford with a stellar sales team selling into the marketplace. UPSO now has California, Chicago, MIT, Stanford, Yale, and many other university presses participating in the program. Fordham content is also available on Project Muse and most recently JSTOR. Having searchable, cross-referenced content available on major library platforms has been beneficial to the Press, its authors, and its core constituents.

One of the smartest decisions I made when I started at FUP was to create a regional imprint. Based on my experience in both trade and academic publishing, I knew that NYC books had the opportunity to sell well and get review attention. FUP had for years been publishing books on New York City and the Hudson Valley, and I recognized the need to create a brand that stood apart from our highly regarded academic list. In 2010 I launched the Empire State Editions (ESE) imprint, and we now have twenty-one books in print, most of which get coverage in The New York Times. Last year we published a history of proposed subway systems that never came to fruition, The Routes Not Taken: A Trip through New York City's Unbuilt Subway System, by Joseph Raskin, that was covered in Choice, The Wall Street Journal, and The New York Times. It sold out of its first printing within a month. The ESE books also allow for local book talks and events like the authors' speaking at the New York Public Library and at independent bookstores such as Spoonbill and Sugartown in Williamsburg. The New York connection also reinforces the Fordham University slogan, "New York Is My Campus, Fordham Is My School." Every mention of FUP in the media reinforces the university name. The ESE imprint also allows for collaborations with other New York institutions. This all helps create advocacy.

Right now FUP is stepping back to evaluate the growth it has experienced, going from $\$ 850,000$ annually to $\$ 1,300,000$ in a five-year period, to determine the best route for moving forward. We plan to evaluate lists and series to determine which are selling and why and which may have run their course. We will continue to develop strategic partnerships that allow our content to be widely distributed in new formats, and we will implement a recently created five-year plan. I have a close relationship with the director of the library as well as with other key members of her team, and we are working on ways to collaborate. I have secured use of the library's digital repository to make deep backlist books available as open access and am looking into other opportunities to make content available. This could include ancillary materials that don't fit naturally into our monographs or collected volumes, or scholarship that does not warrant a dedicated book, such as proceedings of a conference or guest lecture series. These seem to present perfect opportunities to combine the expertise of a university press to vet and edit content and the resources of a library with a robust digital repository to make scholarship available free to a wide audience. We will get there, but it may take a little time. University press publishing is a vital publishing channel. It is up to directors to make this known to faculty and administrators and to do all they can to publish really good books. That's what it comes down to. 


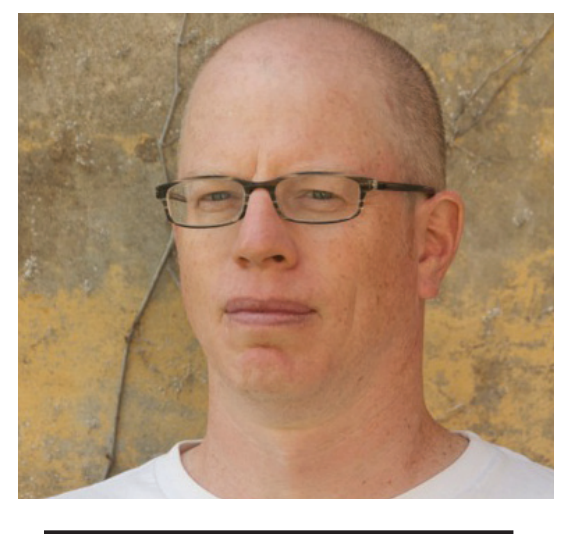

MARK H. SAUNDERS

Director and Editor in Chief University of Virginia Press

University presses have long operated at the somewhat uncomfortable intersection of ideas and commerce, the prestige and gift economies of the academy, and the larger publishing and media markets. Like some of our authors, we also often find ourselves torn between theory and practice. Drawn to innovation in the scholarship we publish as well as the ways in which we publish it, we sometimes run up against unbending ideologies, institutional hurdles, or corporate exigency. Nowhere have these challenges been more acute than in the emerging world of digital publishing.

As the publisher of the Rotunda electronic imprint of the University of Virginia Press for more than a decade, I have lived with these tensions and seen the creativity spawned by their attendant challenges begin to bear fruit. In the larger ecosystem, ebook aggregations such as UPCC/ Project Muse and Books at JSTOR have gained traction with libraries, while last year thoughtful initiatives were launched to move monographs from a pay-to-read to a pay-to-publish model, thereby pushing the debate about open access past the ideological barricades. And while I hesitate to use a unique, local condition as emblematic of the larger trajectory of university presses navigating the various forms of electronic publishing, the University of Virginia Press in 2014 also saw an investment in the long view pay off.

First, some history, or what counts for history in the nanosecond world of the web. Rotunda was founded in 2001 with start-up money-I like to call it our own venture capital-from the Andrew W. Mellon Foundation and the President's Office here at the university. From the start, our funders charged us with extending the tra- ditional strengths of a university press into the digital realm. We knew these strengths included seeking out and developing the finest scholarship, thoughtful peer review, editing manuscripts with artfulness as well as with care, presenting the content according to the best design principles, and marketing the finished product so as to disseminate the work as widely as possible while recovering a good share of the underlying costs. There was some question, however, about what types of content Rotunda would — or could_-publish.

Virginia in 2001 was already known for the E-text Center and the Institute for Advanced Technology in the Humanities (IATH), the founder of which, John Unsworth, was instrumental in conceiving of Rotunda as a home for born-digital scholarship. IATH had already incubated cutting-edge digital humanities projects, several of which Rotunda ultimately published, but their pipeline was not full enough to sustain a publishing list, and if not entirely unique, there were not many other IATHs up and running yet in the scholarly community. Furthermore, market research revealed that our main intended market, academic libraries, preferred large-scale aggregations to one-off projects, no matter how excellent. We realized that we couldn't build the top layer of the digital resources pyramid-new interpretive or synthetic work-before establishing a foundation of digitized texts on which that born-digital scholarship could draw.

Looking to our existing strength in critical and documentary editions, we began building digital collections of the papers of the Founding Fathers, two of which projects - the Papers of George Washington and of James Madison-make their homes at the University of Virginia. For a Literature and Culture Collection, we built on critical editions to create born-digital projects on Herman Melville and Emily Dickinson, both featuring customized textual comparison tools. We digitized the Society of Architectural Historians Buildings of the United States series to create the foundation of SAH Archipedia, an online encyclopedia of the built world that includes GIS mapping and entries illustrated with multiple images. We developed a hybrid business model that took into account librarians' desires to own content from ongoing projects without committing to the recurring costs of subscription.

When sales of these digital editions took off, we drew again on the strengths of our home institution. The Miller Center of Public Affairs, a nonpartisan affiliate of U.Va. that specializes in presidential scholarship, public policy, and political history, hosts the Presidential Recordings Program (PRP). Researchers at the PRP transcribe and annotate the somewhat notorious White House Tapes made by presidents from FDR to Nixon. Adapted to audio, Rotunda offered an ideal platform for a full presentation of the tapes and transcriptions. The first batch came out as the Presidential Recordings of Lyndon B. Johnson Digital Edition (chosen by Choice as an Outstanding Academic Title, I might add) in 2010 .

These primary source materials, whether from the eighteenth or twentieth century, have been prepared to the highest standards of documentary editors, whose expert annotation and indexes reflect a major scholarly investment made over many years. Web presentations of their output in a Rotunda collection not only offer access and discovery, cross-references, topic tagging and other semantic metadata, and other modes of interoperability, they have the power to occasion new scholarly insights. But are we still building, thirteen years later, the foundation layer of the pyramid?

Late in 2013, Marc Selverstone, scholar of the Vietnam era and chair of the Presidential Recordings Program, floated an idea that reflected the spirit of collaboration that is a necessity to publishing, but especially to the publishing of digital work. The fortieth anniversary of Nixon's resignation was coming up in August 2014, and one of the PRP's academic researchers, Ken Hughes, was writing a book on the origins of Watergate. Having spent more than a decade researching and transcribing tapes from the Johnson and Nixon White Houses, Hughes had uncovered a line of argument about Nixon's creation of the Special Investigations Unit - the so-called "Plumbers" - that drew heavily on the tapes and cited thirty-seven conversations directly. Could the University of Virginia Press publish print and ebook editions of the book, with the ebook version linked to the Rotunda presidential recordings platform?

Chasing Shadows: The Nixon Tapes, the Chennault Affair, and the Origins of Watergate came out in July 2014. The ebook edition (http://rotunda.upress.virginia. $\mathrm{edu} /$ ) includes links to the quoted conversations, allowing tablet, smartphone, lap- 
top, and desktop users to listen to Nixon order a break-in, even if (spoiler alert) it's not the one you expect. (A second book by Hughes with similar features, Fatal Politics: The Nixon Tapes, the Vietnam War, and the Casualties of Reelection, was published on the fortieth anniversary of the fall of Saigon, April 2015.) And while I am a firm believer in the power of narrative text, the voices on these tapes will literally make the hair stand up on the back of your neck. For an academic publishing geek, however, what may be more exciting is finally scaling the top of that pyramid, turning theory into practice after thirteen years of work with my colleagues, and reading about the achievement in the same newspapers that blew open the Watergate scandal and published the Pentagon Papers. Innovation may be seen as an instant-gratification business, but long-term investment drawing on long-cherished values of quality and integrity reap dividends no matter what the economy, format, or market.

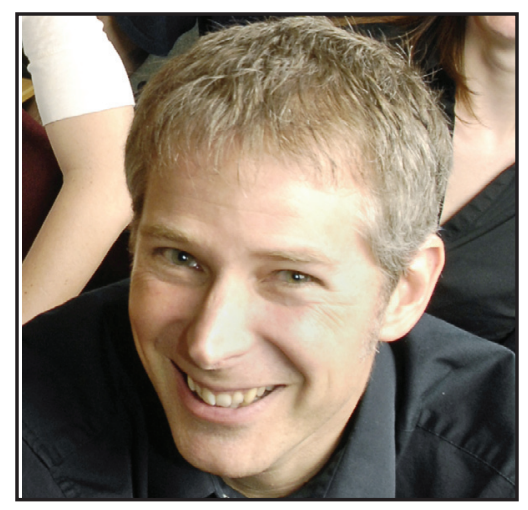

Darrin Pratt

Director, University Press of Colorado

When I reflect on university presses, my thoughts are currently pulled somewhat naturally toward our history and our future. As we ring in 2015, the University Press of Colorado, including our Utah State University Press imprint, is celebrating fifty years of publishing scholarly works in anthropology, composition, folklore, history, and natural history.

Contemplating the path ahead for my own university press, not to mention university presses in general, can be somewhat daunting. The twenty-first century has proved challenging thus far. University presses, along with everyone else, have weathered two recessions, and, unsurpris- ingly, many presses have felt financial pressure. Some have even tried out new organizational structures, with a current trend toward closer alignment with libraries. In 2012, my own press, working closely with the library at Utah State University, merged our operations with those of Utah State University Press. Also, very early in this new century, we witnessed the advent of the ebook, starting with the launch of Amazon's Kindle in 2007, and the business model disruption that engendered. No wonder many university press insiders and outsiders who opine in public venues express concern for the road ahead.

What is particularly interesting to me, though, is the ahistorical nature of that anxiety. Consider, first of all, the fact that university presses are, by and large, a relatively recent invention of the scholarly community. Of the 104 North American members of the Association of American University Presses whose institutional alignment is with a college or university (as opposed to those presses affiliated with learned societies, think tanks, or museums), precisely a quarter of them, or 26, have been established during my lifetime. Over half the university presses in North America, or 56, were founded just since the end of World War II. The average age of the North American university press is just seventyone years. Thus you could say that the hypothetical "average aged" university press was founded in 1944.

When we worry about the future, we university press folks by and large seem to have forgotten the things we used to wring our hands over not all that long ago. I started in university press publishing in 1991 (when the average aged university press was just fifty-one), and at the time our greatest fear was the rise of the chain bookstore, particularly the successful and influential Barnes \& Noble. These days our greatest fear on the retail landscape is Amazon, and I hear people express serious concern for the fate of the very same Barnes \& Noble chain that we once viewed as something of an adversary. In other words, in a little over two decades, a disruptive sales channel became the norm and many of us do not seem to recall those pretty recent days before national bookstore chains. Is it possible that in another twenty years we'll be lamenting the projected demise of the university press's best friend, Amazon.com?
Of course, the advent of chain superstores and their subsequent difficulties in the face of online bookselling is not the only trend that gives university presses pause. Considerable attention has been paid to declining monograph sales to libraries. University presses may or may not have sold substantially more copies into the library market of every book we published back in the 1970s. Some librarians have recently questioned that assertion (see the presentation "Monograph Purchasing Trends in Research Libraries" by Elisabeth A. Jones and Paul N. Courant at http://www.slideshare.net/elisabethjones/ mon-jones-monographpurchasingtrends, although university presses could most likely compile data to counter their claims. But from a business analysis standpoint, precisely how relevant are the 1970 s to our businesses in 2015 anyway? And if library sales were the main driver of university press health and continue to decline, why have universities given birth to so many presses (fifteen, in fact) during the past four decades? Sales to academic libraries by my own press in a more recent periodthe past ten years - are interesting to examine. Although we have had year-over-year unit sales declines as high as 18 percent, we also have had increases as high as 23 percent. Considering the wild swings of the economy over the past decade, our library sales reflect that year-to-year variability more than any discernable recent pattern of growth or decline.

Of course, retail and library sales of our print products may pale in comparison to the business disruption of the ebook and the downward pressure on pricing. Yet in spite of all the concern about ebook pricing, publishers are free to set their own prices, and some scholarly publishers are setting the retail price for their ebooks exactly the same as print. In addition, compared with the mass market segment, ebooks are still less than twenty percent of most press' overall sales. There may be some erosion of margin around the edges, but from where I stand it does not yet appear that we have arrived at any sort of cliff.

Some worry about the technical disruption, but in the greater scheme of things, that piece has been relatively minor to date. The advent of the personal computer happened over four decades ago, and every press I have ever worked at has made heavy use of desktop publishing tools and other technology to get the job done. Ebooks, as 
they exist today, are not terribly sophisticated (industry critic Joe Wikert, currently director of strategy and business development at Olive Software, is fond of calling them "books under glass"), and many presses already have the workflows in place to develop print and electronic projects for simultaneous release. And for those who do not, there are plenty of new cloud solutions out there to make the transition easier. There is no question that the pace of change today, thanks to advances in computer technology, is much more intense and forces one to be more nimble. Yet university presses are no worse off than any other small organizations dealing with the rapidly changing business environments of the modern world, and in many respects we may be better off.

For starters, unlike other publishing companies, we are nonprofits who serve a mission that aligns with that of our parent institutions. We can afford to publish things other publishers cannot, and, in spite of the occasional highly publicized brouhaha, we by and large continue to have great support from our universities. Plus, unlike other nonprofits, we are good at generating revenue. Across all university presses, roughly 83 percent of our revenue is earned income from the sale and licensing of book and serial publications. In an era when nonprofits in general are under increasing pressure to find ways to make their programs pay for themselves as much as possible, university presses already have pretty good models for doing just that. Until open access publishing platforms and strategies develop truly sustainable business models, one could argue that open access — while well intentioned and ostensibly a way to salvage scholarly publishing from its perceived crisis_ could be the biggest threat to sustainable models of scholarly communication precisely because it removes earned income from the equation.
Open Access would thus make university presses, library publishers, and any other new form of noncommercial scholarly publisher particularly exposed to changes in funding streams that are contributed and not earned. Disaster could strike far more suddenly and be far more profound.

In addition, although some may argue that university presses lack the scale and resources for the fuller move to digital scholarship that may still be coming, we are a pretty collegial lot. We may vie for authors and manuscripts from time to time, but by and large we work together more than we compete. University presses have a history of collaboration, particularly when it comes to distribution and order fulfillment. The University of Chicago Press Distribution Center is a testament to that tradition. More recently, the University of Toronto Press developed P-Shift, an XML-first editorial and production workflow that is available as a service to any university press that does not have the capital or staff resources to tackle a digital workflow on their own. Finally, consider the way university presses came together as a group to launch, with the help of ProjectMUSE, an entirely new ebook collection product for the library marketplace. Individually, most of us do lack scale. But together, we have demonstrated that we can tackle big problems.

Finally, university presses have staying power. In his book The Living Company (Harvard Business School Press, 1997), Arie de Geus notes that "the average life expectancy of a multinational corporation-Fortune 500 or its equivalent-is between 40 and 50 years." Continuing the life expectancy analogy, he writes that "human beings have learned to survive, on average, for 75 years or more, but there are very few companies that are that old and flourishing." By this definition, with an average age of 71 years and with scores more presses created in the past century than shuttered, university presses have far more longevity than some very large companies with far more significant capital resources at their disposal.

And we are not just surviving. University presses are thriving. According to data drawn from the AAUP annual statistics, 6,400 new titles were published by sixty-six presses in 2013 (an average of ninety-seven titles per press), and that data does not include the two largest university press members of the AAUP, Cambridge and Oxford. Compare this to data from twenty years earlier, when sixty presses reported publishing just 4,549 new titles (an average of seventy-six titles per press). That's a 28 percent increase in average output over two decades that have been full of anxiety over the decline of the monograph. How can it be a bad thing for scholars that, on average, university presses produced 28 percent more new books annually between 1993 and 2013?

So as I look forward to 2015 and to celebrating fifty years of scholarly publishing at University Press of Colorado, I'm inclined to be optimistic. Amazon, no matter what else you may think of it, has provided one of the most visible marketing and sales channels for the university press catalog that has ever existed. In addition, disruptive or not, ebooks and web publishing models offer opportunities for university presses to get their authoritative content to readers in new ways that would not have been possible in the past. At University Press of Colorado, we are embracing this future and experimenting with ways to more thoroughly enmesh ourselves in the new digital publishing ecosystem, without abandoning the print (and electronic "books under glass") program that has sustained us until now. For university presses and the institutions they serve, the future may be uncertain and more difficult to predict than ever, but on balance I believe that this future looks rather exciting. 